\title{
O falante como etnógrafo da própria língua: uma antropologia da enunciação
}

\author{
The speaker as ethnographer of their own language: \\ an anthropology of enunciation \\ Valdir do Nascimento Flores \\ Universidade Federal do Rio Grande do Sul - Porto Alegre - Rio Grande do Sul - Brasil
}

$\diamond$

\begin{abstract}
Resumo: Este texto, de uma perspectiva enunciativa que visa abordar a propriedade metalinguística da língua, apresenta e desenvolve a ideia segundo a qual o falante, ao falar da materialidade significante da língua, produz um comentário que atribui, no discurso, sentido a essa materialidade. $O$ texto formula, também, uma reflexão acerca da voz, o que a promove à condição de materialidade significante por excelência. Finalmente, é apresentada, em seus aspectos gerais, a ideia de uma antropologia da enunciação, centrada na figura do falante.

Palavras-chave: Materialidade significante; Antropologia da enunciação; Falante; Voz; Contorno de sentido

Abstract: Based on an enunciative perspective that aims at addressing the metalinguistic property of language [langue], this text presents and develops the notion that the speaker, when speaking of the signifier materiality of language, makes a comment that assigns sense to this materiality within the discourse. The text also reflects on the voice, promoting it to the condition of signifier materiality par excellence. Finally, the idea of an anthropology of enunciation, centered on the figure of the speaker, is presented in its general aspects.
\end{abstract}

Keywords: Signifier materiality; Anthropology of enunciation; Speaker; Voice; Outline of sense

\section{Formulando o argumento}

Este trabalho é sobre o fato, aparentemente banal, de o falante usar a língua para falar da língua, o que, segundo o linguista Roman Jakobson, diz respeito à função metalinguística do discurso: "[quando] o remetente e/ou o destinatário têm necessidade de verificar se estão usando o mesmo código, o discurso focaliza o Código; desempenha uma função METALINGUÍSTICA" (JAKOBSON, 1974, p. 126, destaques do autor).

Muitos, além de Jakobson, são os especialistas que se dedicam ao estudo das inúmeras abordagens "meta" no campo da linguagem - Louis Hjelmslev (1975), Harris (1971), Josette Rey-Debove (1978 e 1998), Authier-Revuz (1995) -, e também das abordagens do fenômeno geral da reflexividade das línguas - François Récanati (1979) - e da distinção entre uso e menção - John Lyons (1980) -, entre outros autores. Não é menor a diversidade de termos que circunscrevem fenômenos linguísticos vizinhos, distintos e mesmo opostos: metalinguagem (natural $v s$. lógica); glosa (metalinguística vs. metaenunciativa); reflexividade (transparência vs. opacidade); autonímia (conotação autonímica vs. modalização autonímica), apenas para lembrar esses.

Como é possível ver, o campo que amplamente identifico como da ordem "do uso da língua para falar da língua" - que considero parte da ampla dimensão reflexiva da linguagem - é vasto, heterogêneo e até contraditório. Ele recobre disciplinas bastante diferentes entre si - semiótica, filosofia, linguística, lógica etc. - e perspectivas teóricas igualmente singulares no interior de tais disciplinas.

De minha parte, gostaria, aqui, de evocar um autor pouco lembrado quando o que está em discussão é essa dimensão reflexiva da linguagem: Émile Benveniste. Segundo penso, a questão da reflexividade da língua é 
transversal a todo o pensamento de Benveniste acerca da linguagem. Em sua terminologia, trata-se do que chama de "relação de interpretância". Para ele,

O privilégio da língua é de comportar simultaneamente a significância dos signos e a significância da enunciação. Daí provém seu poder maior, o de criar um segundo nível de enunciação, em que se torna possível sustentar propósitos significantes sobre a significância. É nesta faculdade metalinguística que encontramos a origem da relação de interpretância pela qual a língua engloba os outros sistemas. (BENVENISTE, 1989, p. 66 , grifos meus)

Benveniste é claro ao considerar a relação de interpretância algo específico da língua:

Do ponto de vista da língua, é a relação fundamental, aquela que divide os sistemas em sistemas que articulam, porque manifestam sua própria semiótica, e sistemas que são articulados e cuja semiótica não aparece senão através da matriz de um outro modo de expressão. (BENVENISTE, 1989, p. 62)

Com isso, pode-se defender o princípio segundo o qual a língua é o interpretante de si e de todos os sistemas semióticos: "Nenhum outro sistema dispõe de uma 'língua' na qual possa se categorizar e se interpretar segundo suas distinções semióticas, enquanto que $a$ língua pode, em princípio, tudo categorizar e interpretar, inclusive ela mesma" (BENVENISTE, 1989, p. 62, grifos meus).

A passagem que destaquei nessa citação é essencial para a construção de meu ponto de vista aqui. Vale parafrasear: a língua, em função da relação de interpretância que a caracteriza, pode interpretar todos os sistemas, inclusive a si mesma. E como a língua interpreta a si mesma?

$\mathrm{Na} 12^{\mathrm{a}}$ aula que ministra no Collège de France, no ano de 1969, Benveniste fala na "autossemiotização da língua", que ocorre quando "o falante se detém sobre a língua em vez de se deter sobre as coisas enunciadas" (BENVENISTE, 2014, p. 155). A resposta, portanto, à pergunta feita no parágrafo anterior parece, então, se esboçar: é uma atitude do falante sobre a língua e não sobre um certo conteúdo.

Essa relação de interpretância que, na formulação benvenistiana, daria origem a uma semiologia de segunda geração, de base discursiva, coloca em destaque, em minha opinião, um elemento que não está pensado nos outros tratamentos dados à dita "função metalinguística": o falante.

Da perspectiva que estou querendo fundamentar, o fato de o locutor, o falante, poder falar da língua com a língua confere-lhe um estatuto muito singular: ele é uma espécie de comentador do que ouve e mesmo do que diz. E não se trata de um comentário qualquer, mas de um recurso do qual o falante se vale para dizer algo que a língua fora da propriedade "meta" não permite.

Mas ainda cabe uma delimitação maior para que se entenda o que estou buscando formular com apoio nas ideias de Benveniste: o comentário pelo qual tenho interesse é o que toma a materialidade da língua como elemento a ser comentado e não algum suposto conteúdo enunciado. Esse comentário que o falante faz, acredito, permite-lhe ocupar uma posição que instancia um sentido para a materialidade significante da língua. De certa maneira, o falante, ao falar da face significante da língua, produz uma interpretação, uma espécie de tradução, um segundo nível de enunciação, nas palavras de Benveniste, que, por sua vez, constitui um nível de percepção ainda não contemplado pela linguística.

Esse nível de percepção, que do ponto de vista fenomenológico é um comentário sobre a face significante da língua, eu gostaria de chamar de contorno de sentido. $\mathrm{O}$ falante, ao contornar semanticamente a materialidade da língua, explicita um saber, o seu saber, acerca dela. Esse saber cumpre uma função quase etnográfica na economia - no arranjo ou modo de funcionar de diversos elementos de um conjunto maior - do uso da língua.

A tese defendida aqui, portanto, é: o falante, ao falar da materialidade da língua, é um etnógrafo da própria língua. Essa etnografia é parte de sua inscrição na ordem simbólica que é a cultura. Essa inscrição, por sua vez, se apresenta na interpretação que faz da língua, através dos comentários que a tomam via significante.

Evidentemente, não desconheço o que implica, tecnicamente, usar a palavra etnografia - transcrever textos, selecionar informantes, mapear campos, elaborar diários de campos etc. -, e se a utilizo aqui é menos para defender a ideia, absurda, de que o falante é um etnógrafo no sentido stricto e mais para sublinhar que há a produção de um saber nos contornos de sentido operados por um falante na língua.

O antropólogo norte-americano Clifford Geertz, em quem, quanto a esse tema, me inspiro livremente, diz que a etnografia é uma descrição densa. Para ele, o adjetivo define, nesse contexto, menos as técnicas envolvidas na prática etnográfica e mais o "esforço intelectual e os processos determinados, que definem o empreendimento" (GEERTZ, 1989, p. 4). Com isso, Geertz pode defender a etnografia como um objeto no qual os fenômenos sejam vistos como "uma hierarquia estratificada de estruturas significantes" (p. 5) em termos das quais tais fenômenos “... são produzidos, percebidos e interpretados” (p. 5). Em síntese, para ele, 
[...] fazer uma etnografia é como tentar ler (no sentido de 'construir uma leitura de') um manuscrito estranho, desbotado, cheio de elipses, incoerências, emendas suspeitas e comentários tendenciosos, escrito não com os sinais convencionais do som, mas com exemplos transitórios de comportamento modelado. (GEERTZ, 1989, p. 7)

Em que essa concepção de Geertz pode ser útil para sustentar a ideia de que o falante, ao usar a língua para falar da língua, produz um contorno de sentido, o que o torna um etnógrafo de sua própria língua?

$\mathrm{O}$ falante, ao comentar a língua - e, muito especialmente, a materialidade significante dela -, constrói um saber sobre essa língua, um saber que simultaneamente coloca língua e falante - o intérprete - em destaque. Nos termos de Geertz, seria como supor que o falante constrói uma "hierarquia de estruturas significantes" acerca da língua, determinando-a como um fenômeno produzido, percebido e interpretado a partir das lentes de quem, no caso do falante, está "por dentro" do fenômeno.

\section{Ad exemplum}

Essa formulação um pouco abstrata encontra ilustração em um fenômeno muito familiar, que é o comentário feito pelo falante acerca da voz - sua ou de um outro -, materialidade significante por excelência. Vou dar um exemplo relativo à voz cantada, ou ao que Roland Barthes chamou, em "O grão da voz", de o "espaço (gênero) muito preciso onde uma língua encontra uma voz" (BARTHES, 2009, p. 257, destaques do autor). Trata-se do comentário feito pelo cantor Caetano Veloso a respeito da voz da cantora Gal Costa, presente no Documentário anexo ao DVD Recanto, de Gal Costa, que veio a público em 2013.

O som da voz da Gal leva a gente pra fora, você se sente deixar levar por aquele som, entendeu, que sai assim quase sobrenaturalmente, então você vai pra outras dimensões. Então eu percebi isso na voz de Gal desde que a conheci e vi acontecer diversas vezes ao longo da carreira dela. Ela tá cantando e você parece que sai do tempo. Não é explicado o canto, é acontecido. (COSTA, 2013)

Observe-se, em detalhe, o comentário feito por Caetano Veloso: há uma série de expressões em torno das quais a "voz da Gal" encontra interpretação: "leva a gente pra fora", "você vai pra outras dimensões", "você parece que sai do tempo", "não é explicado", "é acontecido".

Tem-se, aqui, uma situação interessante: as expressões utilizadas pelo cantor para "falar" da voz da cantora são, de maneira mais evidente, uma forma "do uso da língua para falar da língua" - o que, em minha opinião, garante a propriedade "meta" do comentário - e, de maneira menos óbvia, uma tentativa de falar da materialidade significante da língua - nesse caso, a voz atribuindo-lhe um sentido.

É esta segunda maneira que me interessa sobremaneira aqui. Tal atribuição de sentido é, segundo penso, um contorno que o falante faz acerca de algo que não é evidente na língua, a sua materialidade, a respeito do que ele parece não ter a mesma familiaridade que tem quando o que está em causa é o signo em sua função de signo.

Para fazer aparecer com mais clareza o que estou tentando apresentar, é preciso tentar responder à seguinte questão: como o falante procede para falar da língua, tomada em sua materialidade significante? Ou ainda: como procede o falante para falar de elementos da língua que não significam à moda do signo, ou seja, em que significante e significado não estão intimamente, ou desde sempre, ligados?

Explico-me melhor. Considere-se o comentário que o falante faz sobre uma palavra, a exemplo do que é estudado por Josette Rey-Debove, através da sua célebre fórmula tome um signo, fale dele e você terá uma autonímia.

Rey-Debove (2003) entende que o fato autonímico, que constitui um subsistema de uma dada língua que serve para falar dessa língua, se manifesta em dois sistemas semióticos: a autonímia (a metalinguagem) e a conotação autonímica (mundo e metalinguagem).

De um lado, tem-se a autonímia, isto é, a menção de um signo como autodesignação. O exemplo é de Dubois (1998): caso da reflexão que o locutor produz sobre seu próprio discurso: Eu disse "talvez", não disse "sim". As palavras "talvez" e "sim" são usadas autonimicamente. O signo tem, na autonímia, uma semiótica complexa, como se fosse formado por "dois andares": o significante /talvez/ e o significado constituído por um significante/ talvez/ e um significado "talvez".

De outro lado, tem-se a conotação autonímica, isto é, o uso e a menção simultâneos de um signo. Fala-se da "coisa" ao mesmo tempo em que se usa a palavra: conjuga-se a semiótica denotativa (falar do mundo) e a semiótica metalinguística (menção ao signo via autonímia). O exemplo está no Dicionário de linguística da enunciação (2009, p. 167): “é uma 'barbaridade' como diriam os gaúchos". Usa-se a palavra "barbaridade" e, em seguida, menciona-se a palavra.

Em ambos os caso, autonímia e conotação autonímica, o que se vê é o falante valendo-se da consideração da estrutura semiótica da língua para jogar com a maior ou menor opacificação - o termo é de Rècanati (1979) - das unidades lexicais vistas na sua qualidade de unidades semióticas, ou seja, constituídas de significante 
e significado, para usar os termos saussurianos, ou de forma e sentido, para usar os termos benvenistianos. É isso que chamo de significação à moda do signo: o ponto de partida do falante para fazer autonímia ou conotação autonímica é supor a unidade semiótica.

No fenômeno em que o falante utiliza a língua para falar da materialidade significante da língua, o que é colocado em destaque é a falta do "significado" que permitiria advir a unidade semiótica. Em outras palavras, o falante reconhece que uma dada forma significante tem significado, em uma dada instância enunciativa, no entanto, esse significado não sendo dado pelo semiótico do sistema, resta ser atribuído pelo falante, que reconhece seu valor em uma dada situação. Essa atribuição é o que considero um contorno de sentido que o falante produz, o que o alça à condição de um etnógrafo da própria língua, já que o contorno nada mais é que um testemunho da experiência do falante enquanto falante-ouvinte.

Cabe voltar, agora, à passagem em que Caetano Veloso comenta a voz de Gal Costa. "O som da voz da Gal", a materialidade significante destacada pelo falante, é significado no discurso do locutor, de maneira simples e única. O falante fala da língua, de uma parte que reconhece como sendo de natureza linguística - a materialidade significante "o som da voz da Gal" -, e reconhece a falta de atribuição de sentido semiótico dessa materialidade, embora a reconheça, de imediato, como pertencente à língua. Essa falta de sentido é "contornada" pelas expressões que seguem: "não é explicado" e "é acontecido" são apenas as mais bonitas.

Ora, a materialidade significante da língua é destacada pelo falante como algo de extrema relevância para o conjunto do que está acontecendo em uma dada situação, no entanto, falta-lhe um sentido semiótico. O sentido advém do falante, no discurso, ao produzir o contorno de sentido. Com certa liberdade de uso de termos, poder-seia dizer que o significante é desde sempre reconhecido pelo falante, mas o significado é atribuído ao elemento dentro de um contexto singular.

E a materialidade significante? Que espécie de fenômeno é esse? Considero pertencente à materialidade significante tudo o que é da ordem do vocal na língua.

Tenho consciência que essa definição não é suficientemente autoexplicativa. $O$ fato é que o que é da ordem do vocal na língua liga-se a campos muitos distintos religiosos, patológicos, poéticos, entre outros - sem que algo, aparentemente, os ligue entre si. Além disso, minha definição de materialidade significante parece excluir, em princípio, a escrita. Não haveria materialidade significante na escrita?

As respostas que posso ensaiar, neste momento, circunscrevem-se à natureza vocal da linguagem humana. É inegável que o homem fala e que sua fala vale-se da voz.
Como a voz toma corpo na língua? Como se ligam o som e o sentido? Tais perguntas tocam, ao menos de leve, dois aspectos que, em minha opinião, devem ser enfrentados por uma teoria da linguagem que inclua a materialidade significante: de um lado, os termos do compartilhamento - o que, de imediato, impõe consideração à figura do interlocutor e da categoria da escuta - de algo que é único e singular; de outro lado, a natureza sígnica de tudo que diz respeito à língua - o que toca a relação entre o que é da ordem do único com o que é da ordem da possibilidade de haver comunicação (o social, o signo). O contorno de sentido é uma maneira de manter a natureza sígnica da materialidade significante.

Como é possível ver, acredito que se pode estudar o contorno de sentido que o falante dá, na língua e pela língua, à voz de si e/ou à do outro. Esse contorno, essencialmente da ordem do sentido, cabe reiterar, tem um correlato no plano formal, qual seja, a localização do sentido, e mesmo a distribuição, em algo entendido pelo falante como unidades linguísticas construídas no agenciamento da linguagem. Essa localização pode se distribuir linearmente em um determinado nível linguístico ou transversalmente aos níveis linguísticos.

Para que fique bem claro: o contorno de sentido é algo que o falante faz sobre uma unidade que é localizada pelo falante como tal. Não interessa se isso corresponderia, ou não, à verdade científica. O que está em questão é o saber que o falante articula. Em outras palavras: o falante pode produzir uma interpretação sobre um elemento $X$ que, na verdade, em um exame acurado, não estaria implicado no que está sendo dito. O contorno de sentido situa o homem na sua condição de falante, interlocutiva em sua essência.

Pela natureza metalinguística da linguagem, o homem coloca em prática a capacidade de delimitar mecanismos necessários e suficientes para que, cotidianamente, a propriedade da linguagem de se autointerpretar se efetive. É como se o falante, através do contorno de sentido dado à face significante, respondesse simultaneamente a dois implícitos contidos em uma só pergunta: que sentido tem $X$ ? Em outras palavras: há sentido e esse sentido localiza-se em $\mathrm{X}$, sendo $\mathrm{X}$ algo que advém pela materialidade significante, pela voz.

Assim, não se trata mais de fazer uma fonologia, uma sintaxe, uma morfologia, mas de ver que elementos integrados a essas realidades da língua permitem ao falante localizar uma interpretação que diz respeito ao que chamo de contorno de sentido. Corrobora-se, assim, a ideia, quase comum, de que o homem fala para dizer algo; há na fala do homem um propósito dependente da interpretação do outro.

Isso não implica nem simetria nem garantia de comunicabilidade, mas garante ao falante a sua condição de falante e ao outro falante a condição de quem pode 
dizer algo sobre o que foi dito. Chega-se, então, a uma linguística do homem falante. A linguística do homem falante interessar-se-ia pelo que o homem diz da língua, sobre a língua, a respeito da língua. É tempo de dar lugar a essa etnografia. O falante é etnógrafo da própria língua.

\section{Concluindo o argumento}

O primeiro ponto que cabe chamar a atenção: a expressão "contorno de sentido" não é usual no campo da linguística geral. Além disso, é importante ressaltar que, apesar de ser um termo que, na minha formulação, está ligado ao campo da voz, ele não deve ser tomado como algo exclusivo da materialidade acústico-articulatória ou mesmo apenas de natureza fonológica. Contorno de sentido é um termo cunhado para os fins deste trabalho e utilizado para nomear o comentário construído pelo falante, um saber, sobre a materialidade significante da língua.

Parte-se, também, da proposição geral de que a propriedade das línguas de produzir sentido está fortemente vinculada à forma que serve de invólucro ao sentido. Tem-se, assim, o contorno como o que releva da interpretância operada pelo falante, o que implica uma relação específica de forma e sentido.

O contorno é uma espécie de acabamento de conjunto que o locutor dá, em seu discurso, à face reconhecida como significante da língua - a sua e a do outro. Em linhas gerais, ele desempenha uma função modal constitutiva do discurso. Logo, o estudo do contorno de sentido é de natureza semântico-interpretativa.

Esse contorno - que, por vezes, também gostaria de chamar de "narrativo" porque, de certa forma, o falante constantemente conta coisas sobre si e sobre sua língua - que o falante dá à sua enunciação e/ou à enunciação do outro diz respeito à natureza metalinguística da linguagem, à capacidade que esta tem de conter os mecanismos necessários para que o homem coloque em prática, cotidianamente, a propriedade da autointerpretação. É nesse aspecto que considero o falante um etnógrafo da própria língua.

A partir do que apresentei em linhas gerais, acredito que se chega a fazer uma linguística do homem falante, uma linguística que se interessa pelo que o homem diz da língua, sobre a língua, a respeito da língua, com a língua. Chega-se, assim, a uma antropologia - no sentido mais literal possível de "conhecimento do homem", como lembra Todorov (2014) - que não prescindiria da enunciação, da presença do homem na língua, para lembrar Benveniste.

O que há de tangível na face significante da língua, no que habita a voz? Apenas o que o ouvido diz dela. A proposta que este texto não faz mais que esboçar diz respeito a isto: o efeito que a face significante produz ao ouvido. Esse efeito é uma espécie de acabamento de sentido apenas perceptível a uma orelha que devolve o que ouve sob a forma de um sentido, de algo que se poderia considerar uma narrativa. A voz e a orelha são as duas faces de um mesmo fenômeno. Portanto, a voz somente tem existência para o outro.

O leitor deve ter percebido: equiparo a materialidade significante à voz. Esse tema mereceria maior desenvolvimento, o que não farei aqui. No entanto, advirto: voz, para mim, tem um sentido muito especial que não recobre a mera emissão acústico-articulatória. De certa maneira, a voz tem uma essência paradoxal: ela é, ao mesmo tempo, algo que se impõe imperceptivelmente e algo que não se pode deixar de perceber. Explico-me: a voz deve ser suficientemente transparente para que, através dela, com ela, veicule o sentido, e a autoridade maior que delineia o próprio de cada um, mas deve também conter uma certa opacidade sobre a qual se volta em casos muito particulares, não generalizáveis. A voz é, assim, simultaneamente, transparente e opaca.

Cabe olhar para o contorno de sentido que o falante dá, na linguagem e pela linguagem, à voz de si e à do outro. Esse olhar pode fundamentar um antropologia da enunciação que está por vir.

Essa antropologia da enunciação é menos um estudo antropológico no sentido em que comumente se atribui e mais uma perspectiva que não prescinde do fato de o homem falar. A propriedade loquens do homem permite reconhecer outra linguística, que admite o falante, logo, o homem, no seu interior.

A linguística - até mesmo a linguística da enunciação - não raras vezes rejeita o falante sob o argumento de que ao linguista cabe apenas a admissão da representação propriamente linguística. Não é assim que penso. Creio que a antropologia da enunciação seria, antes de tudo, um estudo da natureza loquens do homem, o que tem um interesse humano geral e não apenas disciplinar.

Claude Hagège (1985), em seu livro L'homme de paroles, formula a questão central que, aos meus olhos, dá consistência ao que chamo de antropologia da enunciação. Tomo-a emprestado para os meus fins: que lugar cabe à linguagem na definição de homem?

Se entendi bem a ideia de Benveniste de que a língua é interpretante de si e de todos os demais sistemas semióticos, é possível, nessa interpretação de si, situar o falante como etnógrafo da própria língua. A antropologia da enunciação quem faz é o falante. E uma forma de fazêla, ao menos no que tange à parte da ideia que professa a autossemiotização (o termo é de Benveniste), é produzindo interpretações sobre a própria língua, contornando-a de sentidos. Nessa formulação, há uma possibilidade de simultaneidade entre o objeto e o estudo do objeto: é o fato de o homem poder falar sobre sua língua. 


\section{Referências}

AUTHIER-REVUZ, Jacqueline. Ces mots qui ne vont pas de soï, boucles réflexives et non-coüncidences du dire. Tome 1. Paris: Larousse, 1995.

AUTHIER-REVUZ, Jacqueline. Ces mots qui ne vont pas de soï, boucles réflexives et non-coïncidences du dire. Tome 2. Paris: Larousse, 1995.

BARTHES, Roland. O grão da voz. O óbvio e o obtuso. Lisboa: Edições 70, 2009.

BENVENISTE, Émile. Semiologia da Língua. Problemas de linguística geral II. Tradução de Eduardo Guimarães et al. São Paulo: Pontes, 1989.

BENVENISTE, Émile. Últimas aulas no Collège de France (1968 e 1969). Tradução de Daniel Costa da Silva et al. São Paulo: Unesp, 2014.

COSTA, Gal. Recanto ao vivo [DVD]. Direção: Dora Jobin e Gabriela Gastal. Universal Music, 2013, 1 DVD, 130 min.

DUBOIS, Jean; GIACOMO, Mathée; MARCELLESI, Christiane; MARCELLESI, Jean-Baptiste; MEVEL, JeanPierre. Dicionário de linguística. São Paulo: Cultrix, 1998.

FLORES, Valdir; BARBISAN, Leci; FINATO, Maria; TEIXEIRA, Marlene (Org.). Dicionário de linguística da enunciação. São Paulo: Contexto, 2009.

GEERTZ, Clifford. A interpretação das culturas. Rio de Janeiro: LTC, 2013.
HAGÈGE, Claude. L'Homme de Paroles. Paris: Librairie Arthème Fayard, 1985.

HARRIS, Zellig. Structures mathématiques du langages. Paris: Dunod, 1971.

HJELMSLEV, Louis. Prolegômenos a uma teoria da linguagem. Rio de Janeiro: Perspectiva, 1975.

JAKOBSON, Roman. Linguística e poética. Linguística $e$ comunicação. São Paulo: Cultrix, 1974.

LYONS, John. Semântica I. Lisboa: Editorial Presença, 1980.

RÉCANATI, François. La transparence et l'énonciation, pour introduire a la pragmatique. Paris: Seuil, 1979.

REY-DEBOVE, Josette. Le métalangage, étude linguistique du discours sur le langage. Paris: Le Robert, 1978.

REY-DEBOVE, Josette. La linguistique du signe, une approche sémiotique du langage. Paris: Armand Colin, 1998.

REY-DEBOVE, Josette. Réflexions en forme de postface. In: AUTHIER-REVUZ, Jacqueline; DOURY, Marianne; REBOUL-TOURÉ, Sandrine. Parler des mots, le fait autonymique en discours. Paris: Presses Soubonne Nouvelle, 2013.

TODOROV, Tzvetan. $A$ vida em comum: ensaio de antropologia geral. São Paulo: Unesp, 2014.

Recebido: 30 de junho de 2015

Aprovado: 07 de agosto de 2015

Contato: valdirnf@yahoo.com.br 